\title{
Strategic management in the establishment of a magnet hospital: A nursing staff perspective
}

\author{
Hung-Yu Yang ${ }^{1}$, Chiu-Hui Yu ${ }^{1,2}$, Ming-Jye Wang ${ }^{2 *}$ \\ ${ }^{1}$ Institute of Health Industry Management, Yuanpei University, Hsin-Chu, Taiwan \\ ${ }^{2}$ National Taiwan University Hospital Hsin-Chu Branch, Hsinchu City, Taiwan; *Corresponding Author: jye9129@gmail.com
}

Received 14 June 2013; revised 15 July 2013; accepted 31 July 2013

Copyright (C) 2013 Hung-Yu Yang et al. This is an open access article distributed under the Creative Commons Attribution License, which permits unrestricted use, distribution, and reproduction in any medium, provided the original work is properly cited.

\section{ABSTRACT}

Magnet hospital certification has a reputation for being one solution to nurse recruitment and retention. It is a matter of priority for hospitals to identify and enhance the basic organizational social structures which promote the development and maintenance of magnetism. A total of 436 valid self-administered questionnaires were collected from nurses. Paired sample t-tests, importance-performance gap analysis and ANOVA were applied. The aims of this study were to investigate the key factors in and the gaps between nurses' perceptions and hospital performance in areas contributing to magnetism. The results showed that Salary structure, welfare, and manpower deployment were the key forces of magnetism influencing nursing practice. Public and private hospitals showed significant differences in manpower deployment and nursepatient relationships. Nurses who rotated shifts were more dissatisfied with their hospital scheduling system. Therefore, personnel policies and program are the primary forces in the development of a magnet hospital. Considering the demand for flexible scheduling of nurses, providing a supportive work environment, and keeping pace with today's changing health care environment could achieve better outcomes for nurses, patients, and hospitals. These findings provide a reference to help set priorities for the implementation and development of effective strategies with limited resources. Public hospitals should take the lead in promoting magnet hospitals and set up reasonable salary systems, nursing workforce standards, and administrative support in order to attract and effectively retain nurses.
Keywords: Magnet Hospital; Importance-Performance Gap Analysis; Human Resource Management; Nursing Management

\section{INTRODUCTION}

Worldwide, the developing of magnet hospitals has become the trend for solving the nursing shortage, and it has been viewed as the gold standard for nursing excellence [1]. It also reflects the way that patients seek objective benchmarks that will aid them in finding a hospital with a higher level of care [2]. Considerable evidence has shown that, in magnet hospitals, patients have lower mortality and morbidity rates, shorter lengths of stay, higher patient-satisfaction, and interdisciplinary patient and family-centered care. Nurses who work in magnet hospitals have lower turnover and vacancy rates, higher job-satisfaction, autonomy in the professional practice environment, and good interdisciplinary working relationships $[3,4]$. Therefore, the process of achieving the magnet hospital designation becomes a roadmap for improving the quality of care and working environment in many hospitals [5].

According to the American Nurses Credentialing Center (ANCC), magnet recognition refers to meeting certain criteria by which a hospital is able to withstand nursing shortages, and attract and retain nurses [6]. The criteria include 5 magnet model components and 14 forces of magnetism: 1)Transformational Leadership (encom-passes 2 Forces: Quality of Nursing Leadership, Management Style); 2) Structural Empowerment (encompasses 5 Forces: Organizational Structure, Personnel Policies and Programs, Community and the Healthcare Organization, Image of Nursing, Professional Development); 3) Exemplary Professional Practice (encompasses 5 Forces: Professional Models of Care, Consultation and Resources, Autonomy, Nurses as Teachers, Interdisciplinary Relationships); 4) New Knowledge, Innovations and Im- 
provements (encompasses 1 Force: Quality Improvement); 5) Empirical Outcome (encompasses 1 Force: Quality of Care). In 1993, the fourteen forces of magnetism were drafted and a credentialing service was provided by the ANCC. Today, about $7 \%$ of hospitals (nearly 400 hospitals) have achieved magnet recognition in over the United States as well as some in Lebanon, Singapore, Australia and other countries. Over the last 2 decades, strong evidence has shown that magnet hospitals have excellent nursing staff, a superior work environment, and better patient outcomes [7,8]. This integration of recognition, resources, and culture may be helpful to other hospitals in preparing for magnet recognition and encourage others to do so [9].

To date, the number of hospitals that have achieved magnet recognition is not as good as expected; not only in the United States but even Canada, England, Scotland, and Germany still face the challenge of nursing shortages [10]. Although there are differences in the health care systems, the nursing shortage issue is the same. Identifying the barriers and looking for possible solutions are important issues to deal with if the current nursing shortages are to be resolved. The role of nurses has expanded and the demands on nurses have increased [11,12], so setting priorities has become a major challenge faced worldwide by health plan decision-makers with limited resources [13]. The magnet hospital concept presents itself as a possible solution to the challenge of nursing shortages [10]; however, previous research has focused primarily on provider and patient correlations with magnet hospital characteristics, and less on the identification of an organizational social structure that would promote its development and maintenance [14]. Kanter indicated that social structures in the work-place influenced employee attitudes and behaviors to a greater extent than did natural personality predispositions $[15,16]$; therefore, strengthening the social structures in the hospital work environment was a precursor to magnetism. Kanter also conceptualized power as the "ability to mobilize resources to get things done" [17]. The American Hospital Association recommended that hospitals needed to redesign work processes, develop new modes of working, and increase work efficiency and effectiveness and employee satisfaction in order to make hospitals the employers of choice [18].

Magnet hospitals can create a magnetic working environment that encourages professional nursing and provides excellent nursing practices which serve as the hallmark of high performance institutions [19]. It is also critical to identify the gaps in factors that promote hospital magnetism while considering the allocation of resources and effectively creating a positive work environment that enhances these factors. A two-dimensional strategic matrix [importance-performance gap analysis
(IPGA)] has been applied to health care fields [20,21] as it can quickly offer useful information to decision makers. This study used the IPGA model, from nurses' perspectives, to investigate the key magnetic factors influencing their practice and to identify the gaps between nurses' perceptions and hospital performance in order to provide policy makers and professionals with valuable reference information in order to develop an effective magnet hospital. The aims of this study were: 1) to investigate the key magnetic factors which influenced nursing practice; 2) to analyze the gaps between nurses' perceptions and hospital performance; 3) to examine the relationship between nurses' characteristics, hospital attributes and performance gaps; and 4) to provide key factors to hospital managers, when considering the allocation of resources to help set strategic management goals when establishing a magnet hospital.

\section{METHODS}

\subsection{Study Participants}

The participants were nurses who had at least 1 years experience in a hospital located in the same administrative district covered by national health insurance in Taiwan. Each of 9 district teaching hospitals recruited 50 eligible nurses during August 2012. A total of 450 selfadministered questionnaires were collected, and, of these, 436 were valid.

\subsection{Research Scale Design}

In order to investigate the key magnetic factors influencing nursing practice and identify the gaps between nurses' perception and hospital performance, this study was carried out with a questionnaire using the 14 forces of magnetism drafted by the ANCC [22] and others from a nurse opinion questionnaire [23] as guides. Because it needed to account for a Taiwanese background and health system, the draft was reviewed by academic specialists and practitioners, and pre-tested and revised before the final version was distributed. The contents of the questionnaire included three dimensions: nurses' perceptions of the importance of magnetism, nurses' perceptions as to how the hospital performed, and nurse characteristics. The resulting 18 items were: 1) nursing leadership, 2) power-responsibility assignment, 3) management style, 4) salary structure, 5) welfare, 6) manpower deployment, 7) flexible scheduling, 8) professional care model, 9) facility and equipment, 10) quality improvement, 11) consultation and resources, 12) autonomy, 13) Nurse-patient relationships, 14) clinical teachers' attitudes, 15) interdisciplinary relationships, 16) professional knowledge, 17) opportunity for education, 18) handling nurse-patient disputes. Each item was scored on 
the nurse's perception of importance ( 1 = very unimportant to 5 very important) and the nurse's perception of hospital performance ( $1=$ very dissatisfied to 5 very satisfied).

Nurse characteristics included gender, age, education, salary, marital status, experience, work setting, clinical ladder, and work shift. Hospital attributes were public or private.

\subsection{Data Analysis}

Descriptive statistics, such as mean, standard deviation, frequency and rank order, were used to investigate the key magnetic factors which influenced nursing practice.

Paired sample t-tests were used to analyze the gaps between nurses' perceptions and hospital performance. Factors with statistical significance $(\mathrm{P}<0.05)$ were defined as performance gaps.

Independent samples t-tests and ANOVA were used to examine the relationships among nurses' characteristics, hospital attributes and performance gaps.

The IPGA matrix was used to develop strategic management for magnet hospitals. The IPGA tool is a simple graphic that enables a comparison of perceived importance against performance, and is expected to help make service decisions through a simple strategic matrix. It also includes a gap theory to identify hospital failures based on nurse's expectations vs. their perception of hospital services. Understanding nurse's demands should help hospital managers to provide effective leadership.

The IPGA model includes the following six steps:

Step 1: Collect nurses' perceptions of importance and hospital performance for all 18 forces of magnetism.

Step 2: Calculate the average value of importance of each item $\left(\overline{I_{. j}}\right)$, the average value of performance of each item $\left(\overline{P_{. j}}\right)$, the average value of importance of all items $(\bar{I})$, and the average value of performance of all items $(\bar{P})$.

Step 3: Use paired sample t-tests to determine whether the gap between perception and performance for each item of the 18 forces of magnetism was a positive gap (performance $>$ importance), negative gap (performance $<$ importance) or no gap (performance $=$ importance) .

Step 4: Compute the relative importance (RI) and relative performance (RP), RI $=\bar{I}_{j} / \bar{I}$. Determine if

$\overline{P_{j}}>\overline{I_{j}}$ and the t-test was significant, $\mathrm{RP}(\mathrm{j})=\overline{P_{j}} / \bar{P}$., if $\overline{P_{j}}<\overline{I_{j}}$ and the t-test was significant, $\mathrm{RP}(\mathrm{j})=$ $-\left(\overline{P_{j}} / \bar{P}\right)^{-1}$, or if $\bar{P}_{j}>\bar{I}_{j}$ or $\overline{P_{j}}<\overline{I_{j}}$ and the t-test was non-significant, $R P(j)=0$.

Step 5: Draw the IPGA strategic matrix (Figure 1), where relative importance (nurses' perceptions of importance) is the vertical axis and relative performance (hospital service) is the horizontal axis, and the intersec-

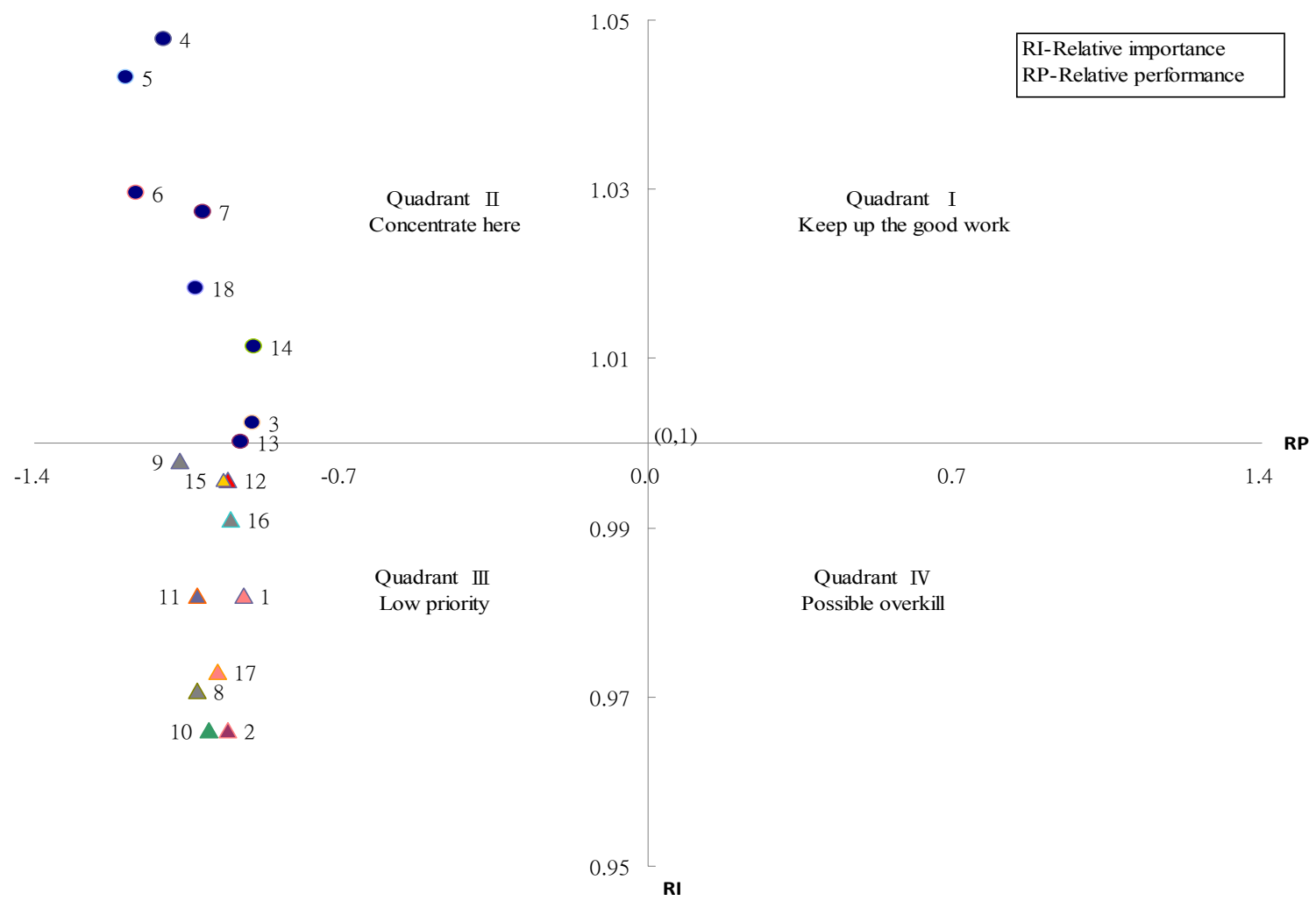

Figure 1. Results of importance-performance gap analysis model. 
tion is fixed at $(0,1)$. The IPGA grid represents the different strategies for resource allocation and management, as illustrated below:

1) Quadrant I is composed of high relative performance and high relative importance items and corresponds to "Keep up the good work".

2) Quadrant II is composed of low relative performance and high relative importance items, and corresponds to "Concentrate here". A point farther away from coordinate $(0,1)$ indicates a greater need for improvement.

3) Quadrant III is composed of low relative performance and low relative importance items, and corresponds to "Low priority".

4) Quadrant IV is composed of high relative performance and low relative importance items, and corresponds to "Possible overkill". A point farther away from co-ordinate $(0,1)$ indicates a greater need to re-allocate resources; and

Step 6: Determine the priorities for resource allocation for the items in Quadrant II.

The distance $\mathrm{D}(\mathrm{j})$ indicates the degree of priority for improvement:

$$
\begin{aligned}
& D_{q}(j) \\
& =\sqrt{\left[\bar{P}_{j} / \max _{r \in q}\left(\left|\bar{p}_{. r}\right|\right]^{2}+\left[\left(\bar{I}_{. j}-1\right) / \max _{r \in q}\left(\left|\bar{I}_{. r}-1\right|\right)\right]^{2}\right.}
\end{aligned}
$$

\section{RESULTS}

\subsection{Study Participant Characteristics}

Among the 436 participants, $45.2 \%$ worked in a public hospital and $54.8 \%$ in a private hospital; $98.8 \%$ were women. Those aged 25 - 34 accounted for $60.7 \%$. Being single accounted for $51.8 \%$ and being married for $48.2 \%$; $50.2 \%$ had Bachelor's degrees. Salaries of 40,001 50,000 NTD were the majority $(45 \%)$, followed by 30,001 - 40,000 NTD (40.7\%). Twelve or more years of experience accounted for $30.9 \%$, and $66.5 \%$ worked on internal and surgical wards. A rotating shift was the majority $(57.3 \%)$ type of work. Clinical ladders N1 and N2 accounted for $28.5 \%$ and $38.7 \%$ respectively (Table 1).

\subsection{Key Forces of Magnetism Influencing Nursing Practice}

For the18 forces of magnetism perceived as important and hospital performance as seen by nurses, Cronbach's $\alpha$ were all $>0.9$. The rankings are shown in Table 2 . The mean values of the nurses' perceptions of importance for all 18 forces of magnetism were above 4.26. These forces were critical factors influencing nursing practice, especially salary structure, welfare, and manpower deployment. They were also associated with lower hospital performance as perceived by the nurses.

\subsection{Priorities Determined by the IPGA Model}

The 18 forces of magnetism had a statistically significant $(\mathrm{P}<0.05)$ gap (Table 3$)$. According to the IPGA model, 8 forces of magnetism in Quadrant II needed urgent improvement (Figure 1). The first priority was salary structure, the second was welfare, and the third was manpower deployment. Other priorities in sequence were flexible scheduling, handling nurse-patient disputes, clinical teachers' attitudes, the Nurse-patient relationships and management style.

\begin{tabular}{|c|c|c|c|c|c|c|c|c|}
\hline & $\mathrm{n}$ & $\%$ & & $\mathrm{n}$ & $\%$ & & $\mathrm{n}$ & $\%$ \\
\hline Hospital & & & Education & & & Clinical ladder & & \\
\hline Public & 197 & 45.2 & $<$ Bachelor & 216 & 49.8 & $\mathrm{~N}$ & 51 & 11.8 \\
\hline Private & 239 & 54.8 & $\geq$ Bachelor & 218 & 50.2 & N1 & 123 & 28.5 \\
\hline Gender & & & Salary(NT) & & & $\mathrm{N} 2$ & 167 & 38.7 \\
\hline Female & 431 & 98.9 & $30,001-40,000$ & 174 & 40.7 & $\geq \mathrm{N} 3$ & 91 & 21.1 \\
\hline Age & & & $50,001-60,000$ & 47 & 11 & Emergency & 54 & 12.4 \\
\hline$\leq 24$ & 48 & 11.4 & $\geq 60,001$ & 14 & 3.3 & $\mathrm{ICU}$ & 92 & 21.1 \\
\hline $25-29$ & 121 & 28.7 & Experience & & & Internal Medicine & 163 & 37.5 \\
\hline $30-34$ & 135 & 32 & $\leq 3$ & 82 & 18.9 & Surgery & 126 & 29 \\
\hline $35-39$ & 74 & 17.5 & $4-6$ & 79 & 18.2 & Work shift & & \\
\hline Marital & & & $10-12$ & 68 & 15.7 & Evening/ night shift & 78 & 18.7 \\
\hline Single & 216 & 51.8 & $\geq 13$ & 134 & 30.9 & day shift & 100 & 24 \\
\hline Married & 203 & 48.2 & & & & & & \\
\hline
\end{tabular}

Table 1. Nurses characteristics and hospital attributes. 
Table 2. Key forces of magnetism influence nursing practice.

\begin{tabular}{|c|c|c|c|c|c|c|}
\hline \multirow{2}{*}{ Items } & \multicolumn{3}{|c|}{ Importance } & \multicolumn{3}{|c|}{ Performance } \\
\hline & Mean & SD & Ranking & Mean & SD & Ranking \\
\hline 1. Nursing leadership & 4.33 & 0.65 & 13 & 3.81 & 0.666 & 3 \\
\hline 2. Power-responsibility assignment & 4.26 & 0.676 & 17 & 3.66 & 0.703 & 6 \\
\hline 3. Management style & 4.42 & 0.651 & 7 & 3.89 & 0.718 & 2 \\
\hline 4.Salary structure & 4.62 & 0.608 & 1 & 3.18 & 0.967 & 16 \\
\hline 5. Welfare & 4.60 & 0.626 & 2 & 2.95 & 1.051 & 18 \\
\hline 6. Manpower deployment & 4.54 & 0.62 & 3 & 3.01 & 0.956 & 17 \\
\hline 7. Flexible scheduling & 4.53 & 0.586 & 4 & 3.46 & 0.807 & 11 \\
\hline 8. Professional care model & 4.28 & 0.661 & 16 & 3.41 & 0.709 & 12 \\
\hline 9. Facility and equipment & 4.4 & 0.632 & 9 & 3.29 & 0.812 & 15 \\
\hline 10. Quality improvement & 4.26 & 0.666 & 17 & 3.50 & 0.685 & 10 \\
\hline 11. Consultation and resources & 4.33 & 0.631 & 13 & 3.41 & 0.720 & 12 \\
\hline 12. Autonomy & 4.39 & 0.596 & 10 & 3.66 & 0.641 & 6 \\
\hline 13. Nurse-patient relationships & 4.41 & 0.615 & 8 & 3.78 & 0.656 & 4 \\
\hline 14. Clinical teachers'attitude & 4.46 & 0.605 & 6 & 3.91 & 0.628 & 1 \\
\hline 15. Interdisciplinary relationships & 4.39 & 0.612 & 10 & 3.62 & 0.675 & 8 \\
\hline 16. Professional knowledge & 4.37 & 0.612 & 12 & 3.69 & 0.689 & 5 \\
\hline 17. Opportunity for education & 4.29 & 0.632 & 15 & 3.58 & 0.712 & 9 \\
\hline 18. Handling nurse-patient disputes & 4.49 & 0.594 & 5 & 3.40 & 0.782 & 14 \\
\hline
\end{tabular}

Table 3. Results of importance-performance gap analysis.

\begin{tabular}{|c|c|c|c|c|c|c|}
\hline Items & t-value & $\mathrm{RI}(\mathrm{j})$ & $\mathrm{RP}(\mathrm{j})$ & Quadrant & Distance D(j) & Priority \\
\hline 1. Nursing leadership & $-14.212^{*}$ & 0.982 & -0.922 & 3 & 0.860 & \\
\hline 2. Power-responsibility assignment & $-14.643^{*}$ & 0.966 & -0.959 & 3 & 1.070 & \\
\hline 3. Management style & $-13.821^{*}$ & 1.002 & -0.903 & 2 & 0.760 & 8 \\
\hline 4. Salary structure & $-24.990^{*}$ & 1.048 & -1.104 & 2 & 1.362 & 1 \\
\hline 5. Welfare & $-26.543^{*}$ & 1.043 & -1.190 & 2 & 1.347 & 2 \\
\hline 6. Manpower deployment & $-25.684^{*}$ & 1.030 & -1.167 & 2 & 1.159 & 3 \\
\hline 7. Flexible scheduling & $-22.620^{*}$ & 1.027 & -1.015 & 2 & 1.027 & 4 \\
\hline 8. Professional care model & $-19.275^{*}$ & 0.971 & -1.03 & 3 & 1.059 & \\
\hline 9. Facility and equipment & $-22.877^{*}$ & 0.998 & -1.067 & 3 & 0.898 & \\
\hline 10. Quality improvement & $-17.916^{*}$ & 0.966 & -1.003 & 3 & 1.098 & \\
\hline 11. Consultation and resources & $-20.503^{*}$ & 0.982 & -1.030 & 3 & 0.942 & \\
\hline 12. Autonomy & $-19.058^{*}$ & 0.996 & -0.959 & 3 & 0.811 & \\
\hline 13. Nurse-patient relationships & $-17.400^{*}$ & 1.000 & -0.929 & 2 & 0.781 & 7 \\
\hline 14. Clinical teachers'attitude & $-15.285^{*}$ & 1.011 & -0.898 & 2 & 0.792 & 6 \\
\hline 15. Interdisciplinary relationships & $-19.135^{*}$ & 0.996 & -0.970 & 3 & 0.820 & \\
\hline 16. Professional knowledge & $-17.387^{*}$ & 0.991 & -0.952 & 3 & 0.821 & \\
\hline 17. Opportunity for education & $-18.186^{*}$ & 0.973 & -0.981 & 3 & 0.998 & \\
\hline 18. Handling nurse-patient disputes & $-23.507^{*}$ & 1.018 & -1.033 & 2 & 0.949 & 5 \\
\hline
\end{tabular}

${ }^{*} \mathrm{P}<0.05$; RI, relative importance; RP, relative performance. 


\subsection{Relationships between Nurse Characteristics, Hospital Attributes and Performance Gaps}

In order to effectively improve the gaps in hospital performance and to further evaluate the relationships between nurse characteristics, hospital attributes and performance gaps, independent samples t-tests and ANOVA were performed. As shown in Table 4, public and private hospitals showed significant differences in manpower deployment and the Nurse-patient relationships. Younger or junior nurses were more satisfied with how hospitals handled nurse-patient disputes. Nurses on rotating shifts were more dissatisfied with their hospital scheduling system. Nurses on internal medicine wards or clinical ladder N2 nurses were less satisfied with manpower deployment. Married nurses and those with a Bachelor's degree, and day nurses felt that they had better nursepatient interactions. Intensive care unit nurses were less satisfied with their clinical teachers' attitudes.

\section{DISCUSSION}

Designation as a magnet hospital has been equated with excellence in nursing practice. To be effective implemented however, there is a need to identify the gaps between the nurses' and hospitals' concerns, and the issue of resource allocation. This study, from the nurses' perspectives, used the IPGA model to investigate the key factors influencing their practice and to identify the gaps between nurses' perceptions and hospital performance in order to develop an effective magnet hospital.

The concept of magnetism can be applied in any health care setting where nurses practice [19,24], in order to identify barriers and enhancing factors that influence the hospital work environment. In this study, the finding that the mean value of the nurses' perceptions of the importance of all 18 forces of magnetism was more than

Table 4. Relationships between nurse characteristics, hospital attributes and performance gaps (in quadrant II of IPGA grid).

\begin{tabular}{|c|c|c|c|c|c|c|c|c|c|}
\hline \multicolumn{10}{|c|}{ Forces of magnetism } \\
\hline \multicolumn{2}{|c|}{$\begin{array}{c}\text { Nurse and } \\
\text { hospital }\end{array}$} & \multirow{2}{*}{$\begin{array}{l}\text { Management } \\
\text { style(3) }\end{array}$} & \multirow{2}{*}{$\begin{array}{c}\text { Salary } \\
\text { structure(4) }\end{array}$} & \multirow[t]{2}{*}{ Welfare(5) } & \multirow{2}{*}{$\begin{array}{c}\text { Manpower } \\
\text { deployment(6) }\end{array}$} & \multirow{2}{*}{$\begin{array}{c}\text { Flexible } \\
\text { scheduling(7) }\end{array}$} & \multirow{2}{*}{$\begin{array}{l}\text { Nurse-patient } \\
\text { relationships(13) }\end{array}$} & \multirow{2}{*}{$\begin{array}{c}\text { Clinical } \\
\text { teachers' } \\
\text { attitudes(14) }\end{array}$} & \multirow{2}{*}{$\begin{array}{c}\text { Handling } \\
\text { nurse-patient } \\
\text { disputes(18) }\end{array}$} \\
\hline characte & eristics & & & & & & & & \\
\hline \multirow{2}{*}{$\begin{array}{c}\text { Hospital } \\
\text { attributes }\end{array}$} & t-value & 0.896 & 0.043 & 1.461 & $6.088^{*}$ & 1.534 & $4.828^{*}$ & 2.826 & 0.183 \\
\hline & & & & & Private $>$ public & & Private $>$ public & & \\
\hline \multirow[t]{2}{*}{ Age } & F-value & 0.659 & 0.744 & 1.183 & 1.229 & 1.338 & 1.139 & 1.275 & $2.930^{*}$ \\
\hline & Post-Test & & & & & & & & $24 \downarrow>40 \uparrow$ \\
\hline \multirow[t]{2}{*}{$\begin{array}{c}\text { Marital } \\
\text { status }\end{array}$} & $\mathrm{t}$-value & 2.769 & 0.183 & 0.053 & 0.508 & 0.016 & $4.435^{* *}$ & 0.157 & 0.203 \\
\hline & & & & & & & Married $>$ single & & \\
\hline \multirow[t]{2}{*}{ Education } & $\mathrm{t}$-value & 0.01 & 0.202 & $9.689^{* * *}$ & 0.652 & 1.764 & $11.105^{* * *}$ & 3.329 & 0.141 \\
\hline & Post-Test & & & $\begin{array}{l}\text { Bachelor } \uparrow> \\
\text { under Bachelo }\end{array}$ & & & $\begin{array}{l}\text { Bachelor } \uparrow> \\
\text { under Bachelor }\end{array}$ & & \\
\hline \multirow[t]{2}{*}{ Salary } & F-value & 1.125 & $4.475^{* *}$ & $3.390^{*}$ & $2.978^{*}$ & 2.257 & 1.567 & 1.935 & 2.305 \\
\hline & Post-Test & & $\begin{array}{c}{ }^{\mathrm{ps}} 4>1, \\
4>2,4>3\end{array}$ & ${ }^{\mathrm{ps}} 4>1,4>3$ & ${ }^{\mathrm{ps}} 4>3$ & & & & \\
\hline \multirow[t]{2}{*}{ Experience } & F-value & 0.671 & 0.784 & 0.830 & 1.704 & 1.547 & 0.671 & 1.078 & $2.670^{*}$ \\
\hline & Post-Test & & & & & & & & $3 \mathrm{y} \downarrow>13 \mathrm{y} \uparrow$ \\
\hline \multirow[t]{2}{*}{$\begin{array}{l}\text { Work } \\
\text { shift }\end{array}$} & F-value & 0.068 & 0.888 & 0.705 & 0.158 & $4.604^{*}$ & $5.135^{* * *}$ & 1.103 & 0.759 \\
\hline & Post-Test & & & & & $\begin{array}{c}\text { Day shift } \\
>\text { rotating shift }\end{array}$ & $\begin{array}{l}\text { Day shift }> \\
\text { rotating shift }\end{array}$ & & \\
\hline \multirow[t]{2}{*}{$\begin{array}{l}\text { Work } \\
\text { setting }\end{array}$} & F-value & 2.008 & 1.552 & 2.330 & $3.745^{*}$ & 0.212 & 1.677 & $3.140^{*}$ & 2.313 \\
\hline & Post-Test & & & & $\begin{array}{l}\text { ICU > Internal } \\
\text { Medicine wards }\end{array}$ & & & Surgery $>$ ICU & \\
\hline \multirow{2}{*}{$\begin{array}{l}\text { Clinical } \\
\text { ladder }\end{array}$} & F-value & 1.093 & 1.171 & 1.603 & $3.110^{*}$ & 2.22 & 1.322 & 1.022 & 1.815 \\
\hline & Post-Test & & & & $\begin{array}{c}\mathrm{N}>\mathrm{N} 2 \\
\mathrm{~N} 3 \uparrow>\mathrm{N} 2\end{array}$ & & & & \\
\hline
\end{tabular}

${ }^{*} \mathrm{P}<0.05,{ }^{* *} \mathrm{P}<0.01,{ }^{* * *} \mathrm{P}<0.001$. Note: the table shows significant items. PS: 4: above 60001(NTD), 3: 50001-60000(NTD), 2: 40001-50000(NTD), 1: 30001-40000(NTD). 
4.26, demonstrated that these forces were critical factors which influenced nursing practice. Salary structure, welfare, and manpower deployment were especially important and also perceived by the nurses as part of poor hospital performance. These 3 items had implications for personnel policies and program. This was consistent with the Gheith and Zakaria study which showed that the lack of personnel policies was perceived as a magnetic barrier by a high percentage of staff nurses [1]. Aikin and Poghosyan indicated that forces of magnetism appeared to have the same potential for transforming nursing practice in countries with limited resources as they did in wealthier countries [25]. The magnet recognition program has established the schema for an excellent nursing service [26].

The role of nurses has expanded into multi-tasking, and nurses are the first ones who are thought of in the health care industry. It is necessary that their needs be addressed because their job content and satisfaction are absolutely important [12]. Sleutel noted that the nursing practice environment was really just one set of related concepts that had been described as "organizational factors that influenced nursing practice" [27]. This research indicated that there were 8 gap items which urgently required improvement by the hospitals. On further analysis of the relationships between the 8 gap items and hospital attributes/nursing characteristics, the results showed that nurses working in private hospitals perceived that those hospitals provided higher performance than did public hospitals in manpower deployment and nurse-patient interactions. This may be because a public hospital, which is usually under resourced and overused, serves the majority of the population [28], has more restrictive rules [29], is burdened by public health care, has patients who require more specialized care and long-term treatment, and is often characterized as being inefficient and ineffective which leads to excessive workloads [30]. Another reason may be that a public hospital does not meet the aspirations and values system of nurses who work there, and those who are not satisfied at work are also found to distance themselves from their patients [31]. Baxter also highlighted the strong influence of nurse job satisfaction on the quality of care they provided as well as on the nurse-patient relationships [32,33]. A shortage of nurses and heavy workloads lead to occupational stress which affects job satisfaction [34]; therefore, professional practice is impossible without support systems that remove barriers between nurses and patients [35]. On the other hand, the private hospital is known for its world-class facilities, affords the opportunity to improve the provision of care in an optimal setting with adequate resources and time, and provides more efficient, effective health care in a more comfortable environment to ensure that the patients become the priority and patients' needs are met [30].

In terms of personnel policies and program (salary structure, welfare, and manpower deployment), hospital performance was more satisfactorily perceived by nurses with a higher salary compared to those with a lower salary. Although salary may not always be a motivator, employees will be happier and have reduced levels of dissatisfaction with more money [36]. Personnel policies at the nurses' level had the strongest effect in predicting job satisfaction [28,37], as salaries and benefits influenced their intent to stay in their current positions $[1,38]$. Hospitals should therefore be clear that the salary structure and benefits are fair as perceived by nurses.

Rotating shifts have been a source of hesitation in choosing nursing as a professional career, for work schedules are related not only to nurses' sleep, circadian disruptions, and fatigue but also to their ability to meet their families' needs [39]. This causes nurses distress and is one of factors related to job satisfaction [40,41]. In this study, the results showed that most nurses who rotated shifts were more dissatisfied than those who worked days. It is necessary for hospital managers to think twice about policies regarding mandated overtime and rotations in order to promote job satisfaction and further encourage nurses to stay in this professional field.

Nurses are often seen as the frontline by patients and are usually expected to provide high quality care as well as be the principal link between the technical and interpersonal aspects of that care [42]. Nurse-patient disputes can happen in a variety of situations. This is a nurse's concern when it occurs, but it may not all be the nurse's responsibility. Our results demonstrated that younger or junior nurses were more satisfied with how hospitals handled nurse-patient disputes than were older or senior nurses. This may be due to the fact that younger or junior nurses were newly trained and assigned to care for patients with simpler conditions which were easily cared for and less likely to cause a dispute. Or, younger or junior nurses had higher levels of zeal and a sense of mission [43-45] as well as perceiving their work environment as healthier [43]. The hospital should frequently mediate in nurses-patient disputes.

The nurse-patient relationships are a central element of professional nursing practice in health care delivery [46], and nursing is both an art and a science based on years of theoretical and scientific research [47]. This study showed that married nurses, those with a Bachelor's degree, and day nurses felt that they had better nurse-patient interactions, probably because they had more related work experience, knowledge, and communication skills training. Pillay also found that a nurse's work experience was a significant factor influencing the level of satisfaction by creating a sense of security in nursing and better relationships with patients [30]. 
Nurses in intensive care units were less satisfied with their clinical teachers' attitudes and nurses on internal medicine wards were less satisfied with manpower deployment. Patients in the ICU have life-threatening conditions and need constant, close monitoring and more equipment and medication than those on general wards. ICUs have higher levels of staffing and nurses are highly trained in caring for the most severely ill patients as well as having higher levels of job stress, so it is important to interact with clinical preceptors to grow in a professional role. As one has more job stress, emotional reactions inevitably lead to a poor attitude. According to Cook [48], clinical preceptors' teaching styles and attitudes were major factors affecting anxiety among students, as well as the perceived effectiveness of the clinical instructors by both students and instructors [49]. In terms of manpower deployment, work on an internal medicine ward is multifaceted and demanding, and requires special professional know-how [50]. Those nurses felt less satisfaction with what the hospital provided.

The clinical ladder is an impetus for professional development [51], but advancing from N2 to N3 (N4) was an important barrier. In addition to professional training those nurses should begin learning about teaching, research, and administration. This study showed that clinical ladder N2 nurses were less satisfied with manpower deployment. This may be because of overwork and the absence of related knowledge and skill or the lack of time to prepare for examinations, test anxiety, and a shortage of access to enough pre-course materials [52]. Riley et al. [53] also found nurses' perceptions of satisfying aspects of the clinical ladder included recognition at all levels in the presence of peers, personal satisfaction, professional growth, financial incentives, and administration.

This study had some limitations. First, study participation depended on the nurse's consent, so there may have been a sampling bias. Second, results from the same administrative district hospitals may not be generalized to other hospitals. Third, the forces of magnetism related to the benefits to nurses may have resulted from the Hawthorne Effect.

\section{CONCLUSIONS}

Compared to previous literature focusing on the outcomes in magnet and non-magnet hospitals, this study aimed to provide more specific management guidelines by applying the IPGA approach for hospital managers with limited resources.

In this study, forces of magnetism proposed by the ANCC and other sources clearly demonstrated a gap between nurses' perceptions and hospital performance. Personnel policies and program are keys to the implementation of the magnet hospital concept as there are differences in hospital attributes, salary, and positions on the clinical ladder. Considering the demand for flexible scheduling for nurses, providing a supportive work environment, and keeping pace with today's changing health care environment could achieve better outcomes for nurses, patients, and hospitals.

\section{REFERENCES}

[1] Gheith, N.A.-R. and Zakaria, A.M. (2012) Developing a guideline to enhance hospital magnetic features at pediatric hospital of Mansoura University. Journal of Applied Sciences Research, 8, 4478-4485.

[2] UC Davis Medical Center (n.d.) Frequently asked questions (FAQs) about magnet.

http://www.ucdmc.ucdavis.edu/nurse/magnet/faq.html

[3] Heede, K.V., Florquin, M., Bruyneel, L., Aiken, L.H., Diya, L., Lesaffre, E. and Sermeus, W. (2013) Effective strategies for nurse rentention in actue hospitals: A mixed method study. International Journal of Nursing Studies, 50, 185-194. doi:10.1016/j.ijnurstu.2011.12.001

[4] Massachusetts General Hospital (n.d.) Magnet hospital re-designation visit.

http://www.mghpcs.org/PCS/Magnet/Documents/PDF/Re -designation Brochure.pdf

[5] Wolf, G.A. and Greenhouse, P.K. (2006) A road map for creating a magnet work environment. JONA, 36, 458-462. doi:10.1097/00005110-200610000-00006

[6] ANCC (n.d.) Magnet recognition program model. http://www.nursecredentialing.org/Magnet/ProgramOverv iew/New-Magnet-Model

[7] Drenkard, K. (2010) The business case for magnet. Journal of Nursing Administration, 40, 263-271. doi:10.1097/NNA.0b013e3181df0fd6

[8] Kelly, L.A., McHugh, M.D. and Aiken, L.H. (2011) Nurse outcomes in magnet and non-magnet hospitals. The Journal of Nursing Administration, 41, 428-433. doi:10.1097/NNA.0b013e31822eddbc

[9] Ricke-Kiely, T. and Robey-Williams, C. (2011) Leading the change reaction. Nursing Management, 42, 41-45.

[10] Aiken, L.H., Clarke, S.P., Sloane, D.M., Sochalski, J.A., Busse, R., Clarke, H. and Shamian, J. (2001) Nurses' reports on hospital care in five countries. Health Affairs, 20, 43-53. doi:10.1377/hlthaff.20.3.43

[11] Cameron, S.J., Horsburgh, M.E. and Armstrong-Stassen, M. (1994) Job satisfaction, propensity to leave and burnout in RNs and RNAs: A multivariate perspective. Canadian Journal of Nursing Administration, 7, 43-64.

[12] Lakshmi, K.S., Ramachandran, T. and Boohene, D. (2012) Analysis of work life balance of female nurses in hospitals-comparative study between government and private hospital in Chennai, TN., India. International Journal of Trade, Economics and Finance, 3, 213-218.

[13] Singer, P.A. (2000) Recent advances in medical ethics. British Medical Journal, 321, 282-285. doi:10.1136/bmj.321.7256.282

[14] Laschbinger, H.K., Almost, J. and Tuer-Hodes, D. (2003) 
Workplace empowerment and magnet hospital characteristics. JONA, 33, 410-422. doi:10.1097/00005110-200307000-00011

[15] Kanter, R. (1977) Men and women of the corporation. Basic Books, New York.

[16] Kanter, R. (1993) Men and women of the corporation. 2nd Edition, Basic Books, New York.

[17] Kanter, R. (1979) Power failure in management circuits. Harvard Business Review, 57, 65-75.

[18] American Hospital Association (2010) Workforce 2015: Strategy trumps shortage. American Hospital Association, Washington, DC

[19] Aiken, L.H. (2002) Superior outcomes for magnet hospitals: The evidence base. In: McClure, M.L. and Hinshaw, A.S., Eds., Magnet Hospitals Revisited: Attraction and Retention of Professional Nurses, American Nurses Publishing, Washington, DC, 61-82.

[20] Lin, S.P., Chan, Y.H. and Tsai, M.C. (2009) A transformation function corresponding to IPA and gap Analysis. Total Quality Management \& Business Excellence, 20, 829846. doi:10.1080/14783360903128272

[21] Lin, S.P. and Wang, M.J. (2012) Strategic management of behavioural change in type 2 diabetic patients. Public Health, 126, 18-24. doi:10.1016/j.puhe.2011.09.021

[22] ANCC (n.d.) Forces of magnetism. http://www.nursecredentialing.org/Magnet/ProgramOverv iew/HistoryoftheMagnetProgram/ForcesofMagnetism

[23] ANCC (n.d.) Nurse opinion questionnaire. http://ancc.nursecredentialing.org/Magnet/NurseOpinionS urvey/TakeMagnetSurvey.aspx

[24] Frazier, S.C. (2003) Magnet home care agencies. Home Healthcare Nurse, 21, 603-610. doi:10.1097/00004045-200309000-00010

[25] Aiken, L.H. and Poghosyan, L. (2009) Evaluation of "magnet journey to nursing excellence program" in Russia and Armenia. Journal of Nursing Scholarship, 41, 166-174. doi:10.1111/j.1547-5069.2009.01268.x

[26] Ma, C.-C., Hwang, P.-W. and Alexander, J.W. (2010) Taiwanese nurses' cognition and attitudes towards the Magnet Hospitals Recognition Programme. International Nursing Review, 57, 78-84.

doi:10.1111/j.1466-7657.2009.00746.x

[27] Sleutel, M.R. (2000) Climate, culture, context, or work environment? Organizational factors that influence nursing practice. Journal of Nursing Administration, 30, 5358. doi:10.1097/00005110-200002000-00002

[28] Bahalkani, H.A., Kumar, R., Lakho, A.R., Mahar, B., Mazhar, S.B. and Majeed, A. (2011) Job satisfaction in nurses working in tertiary level health care settings of Islamabad, Pakistan. Journal of Ayub Medical College Abbottabad, 23, 130-133.

[29] Maryyan, M.T. (2005) Nurse job satisfaction and retention: Comparing public to private hospitals in Jordan. Journal of Nursing Management, 13, 40-50. doi:10.1111/j.1365-2834.2004.00453.x

[30] Pillay, R. (2009) Work satisfaction of professional nurses in South Africa: A comparative analysis of the public and private sectors. Human Resources for Health, 7, 1-10. doi:10.1186/1478-4491-7-15

[31] Demerouti, E., Bakker, A., Nachreiner, F. and Schaufeli, W.B. (2000) A model of burnout and life satisfaction amongst nurses. Journal of Advanced Nursing, 32, 454464. doi:10.1046/j.1365-2648.2000.01496.x

[32] Baxter, V. (2002) Nurses' perception of their role and skills in a medium secure unit. British Journal of Nursing, 11, 1312-1321.

[33] Takase, M., Maude, P. and Manias, E. (2005) Explaining nurses' work behaviour from their perception of the environment and work values. International Journal of Nursing, 42, 889-898. doi:10.1016/j.ijnurstu.2004.12.008

[34] Nabirye, R.C., Brown, K.C., Pryor, E.R. and Maples, E.H. (2011) Occupational stress, job satisfaction and job performance among hospital nurses in Kampala, Uganda. Journal of Nursing Management, 19, 760-768. doi:10.1111/j.1365-2834.2011.01240.x

[35] Clifford, P.G. (1992) The myth of empowerment. Nursing Administration Quarterly, 16, 1-5. doi:10.1097/00006216-199201630-00003

[36] Lephalala, R.P. (2006) Factors influencing nursing turnover in selected private hospitals in England. Master's Thesis, University of South Africa, Pretoria.

[37] Chen, Y.-M. and Johantgen, M.E. (2010) Magnet hospital attributes in European hospitals: A multilevel model of job satisfaction. International Journal of Nursing Studies, 47, 1001-1012. doi:10.1016/j.ijnurstu.2009.12.016

[38] Wang, S.H., Sermsri, S., Sirisook, V. and Sawangdee, Y. (2003). Job satisfaction of staff nurses and their perception on head nurses leadership: A study in Sakaeo provincial hospital. Thailand Journal of Public Health and Development, 11, 88-100.

[39] Ruggiero, J.S. and Pezzino, J.M. (2006) Nurses' perceptions of the advantages and disadvantages of their shift and work schedules. Journal of Nursing Administration, 36, 450-453. doi:10.1097/00005110-200610000-00004

[40] Barton, J. and Folkard, S. (1991) The response of day and night nurses to their work schedules. Journal of Occupational Psychology, 64, 207-218. doi:10.1111/j.2044-8325.1991.tb00555.x

[41] Krausz, M., Sagie, A. and Bidermann, Y. (2000) Actual and preferred work schedules and scheduling control as determinants of job-related attitudes. Journal of Vocational Behavior, 56, 1-11. doi:10.1006/jvbe.1999.1688

[42] Tzeng, H.-M. (2006) Model testing on the crisis interventions and actions to prevent medical disputes: A Taiwanese nursing perspective. Journal of Clinical Nursing, 15, 554-564. doi:10.1111/j.1365-2702.2006.01365.x

[43] Kramer, M., Maguire, P. and Brewer, B.B. (2011) Clinical nurses in magnet hospitals confirm productive, healthy unit work environments. Journal of Nursing Management, 19, 5-17. doi:10.1111/j.1365-2834.2010.01211.x

[44] Lowe, G.S., Schellenberg, G. and Shannon, H.S. (2003) Correlates of employees' perceptions of a healthy work environment. American Journal of Health Promotion, 17, pp. 390-399. doi:10.4278/0890-1171-17.6.390 
[45] Schmalenberg, C. and Kramer, M. (2008) Essentials of a productive nurse work environment. Nursing Research, 57, 2-13. doi:10.1097/01.NNR.0000280657.04008.2a

[46] Shattell, M. (2004). Nurse-patient interaction: A review of the literature. Journal of Clinical, 13, 714-722.

[47] Triolo, P.K. (2008) Student Nurse Pathway. http://www.upmc.com/careers/nursing/Documents/Studen tNursePathways-2008-10.pdf

[48] Cook, L. (2005) Inviting teaching behavious of clinical faculty and nursing students' anxiety. Journal of Nursing Education, 44, 156-161.

[49] Smith, C.S., Swain, A. and Penprase, B. (2011) Congruence of perceived effective clinical teaching characteristics between students and preceptors of nurse anesthesia programs. Journal of the American Association of
Nurse Anesthetists, 79, 62-68.

[50] Huukkala, K. (2010) The professional know-how of a nurse working in an internal medicine ward. Master's Thesis, University of Turku, Turku.

[51] Watts, M.D. (2010) Certification and clinical ladder as the impetus for professional development. Critical Care Nuring Quarterly, 33, 52-59.

[52] Miracle, V.A. (2007) Thinking about certification. Dimensions of Critical Care Nursing, 26, 72-75. doi:10.1097/00003465-200703000-00008

[53] Riley, J.K., Roldand, D.H., James, D. and Norton, H.J. (2009) Clinical ladder: Nurses' perceptions and satisfiers. Journal of Nursing Administration, 39, 182-188. doi:10.1097/NNA.0b013e31819c9cc0 